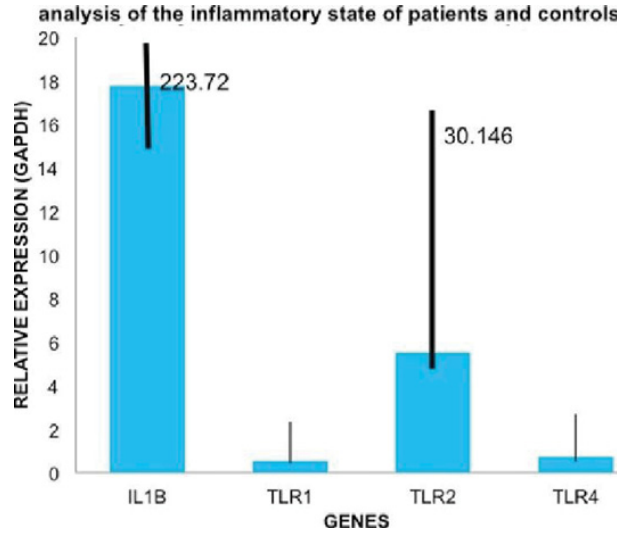

References:

[1] Neogi T., et al. Gout Classification. Criteria An American College of Rheumatology/European League Against Rheumatism. Arthritis \& Rheumatology. 2015.

[2] Busso N., et al. Review Mechanisms of inflammation in gout. Arthritis Research \& Therapy 2010.

[3] Mitroulis I., et al. Review, Neutrophils, IL-1ß, and gout: is there a link. Semin Immunopathology. 2013.

[4] Partial HPRT. Deficiency with a Novel Mutation of the HPRT Gene in Combination with Four Previously Reported Variants Associated with Hyperuricemia. International Medicine. 2014

Disclosure of Interest: None declared

DOI: 10.1136/annrheumdis-2017-eular.3594

\section{AB0862 THE SENSITIVITY OF THE DOUBLE CONTOUR SIGN IN HAND JOINTS WOULD BE BETTER BY THE DORSAL SURFACE EXAMINATION}

A.M. Mahdi ${ }^{1}, 2$, H. Rkain ${ }^{1}$, M. Erraoui ${ }^{1}$, R. Watfeh ${ }^{3}$, S. Aktaou ${ }^{3}$, L. Tahiri ${ }^{1}$, R. Bahiri ${ }^{1}$, F. Allali ${ }^{1}$, N. Hajjaj-Hassouni ${ }^{1} .{ }^{1}$ Rheumatology, Faculty of Medicine and Pharmacy; ${ }^{2}$ University Mohamed V, Rabat; ${ }^{3}$ Faculty of Medicine and Pharmacy, Rabat, Morocco

Objectives: To compare the prevalence of ultrasonographic gout specific sign double contour between the dorsal and palmar surfaces of the hand joints. Methods: This is a cross-sectional study which includes 15 patients with chronic gout, defined according to the American College of Rheumatology criteria (ACR 1977). Ultrasound (US) examination was performed using a high-frequency linear probe (Toshiba Xario ${ }^{\circledR}$, frequency $(8-14 \mathrm{MHz})$ ) in B and Doppler modes. 560 articular sites were studied at their dorsal and palmar surfaces. We compared the prevalence of the hyperechoic band over the superficial margin of the articular cartilage described as a double contour (DC) between the dorsal and palmar surfaces at each site studied.

Results: The mean age at onset was $54.7 \pm 12,6$ years, and the median diagnosis duration was 0 (0.3) years).

The results of the US examination are summarized in Table 1

Table 1. comparison of double contour prevalence between the dorsal and palmar surfaces of wrist, MCP, PIP and DIP joints in the studied population

\begin{tabular}{lccc}
\hline Joints $(\mathrm{N}=540)$ & Dorsal surface $(\%)$ & Palmar surface $(\%)$ & $P$ \\
\hline Wrist joints $(\mathrm{N}=120)$ & 12,6 & 7,3 & $<\mathbf{0 . 0 0 1}$ \\
Radiocarpal $(\mathrm{N}=30)$ & 20 & 6,7 & 0,6 \\
Ulnocarpal $(\mathrm{N}=30)$ & 13,3 & 6,7 & $\mathbf{0 , 0 1}$ \\
Scaphotrapezial $(\mathrm{N}=30)$ & 3,3 & 13,3 & 0,8 \\
Trapeziometacarpal $(\mathrm{N}=30)$ & 13,3 & 3,3 & 0,1 \\
MCP $(\mathrm{N}=150)$ & 8 & 6,6 & $<\mathbf{0 . 0 0 1}$ \\
MCP 1 $(\mathrm{N}=30)$ & 3,3 & 10 & 0,1 \\
MCP 2 $(\mathrm{N}=30)$ & 13,3 & 6,7 & $\mathbf{0 , 0 1 4}$ \\
MCP 3 $(\mathrm{N}=30)$ & 6,7 & 6,7 & $\mathbf{0 , 0 0 2}$ \\
MCP 4 $(\mathrm{N}=30)$ & 6,7 & 0 & $<\mathbf{0 . 0 0 1}$ \\
MCP 5 $(\mathrm{N}=30)$ & 10 & 10 & $<\mathbf{0 . 0 0 1}$ \\
PIP $(\mathrm{N}=150)$ & 4 & 7,3 & $<\mathbf{0 . 0 0 1}$ \\
IP $(\mathrm{N}=30)$ & 3,3 & 10 & 0,1 \\
PIP 2 $(\mathrm{N}=30)$ & 6,3 & 3,3 & 0,9 \\
PIP 3 $(\mathrm{N}=30)$ & 6,7 & 13,3 & $\mathbf{0 , 0 1}$ \\
PIP 4 $(\mathrm{N}=30)$ & 3,3 & 10 & 0,1 \\
PIP 5 $(\mathrm{N}=30)$ & 0 & 0 & $<\mathbf{0 . 0 0 1}$ \\
DIP $(\mathrm{N}=120)$ & 0,8 & 3,3 & $\mathbf{0 , 0 3 3}$ \\
DIP 2 $(\mathrm{N}=30)$ & 0 & 0 & $<\mathbf{0 . 0 0 1}$ \\
DIP 3 $(\mathrm{N}=30)$ & 3,3 & 3,3 & $\mathbf{0 , 0 0 2}$ \\
DIP 4 $(\mathrm{N}=30)$ & 0 & 3,3 & $<\mathbf{0 . 0 0 1}$ \\
DIP 5 $(\mathrm{N}=30)$ & 0 & 6,7 & $<\mathbf{0 . 0 0 1}$ \\
\hline
\end{tabular}

Conclusions: Our study suggests that globally, DC predilect significatily in dorsal than in palmar surfaces of hand joints. These results should be verified on a larger population.
Disclosure of Interest: None declared

DOI: 10.1136/annrheumdis-2017-eular.3881

\section{AB0863 THE POPLITEUS GROOVE IN THE LATERAL FEMORAL CONDYLE: A SHELTER FOR MONOSODIUM URATE CRYSTALS?}

A. Di Matteo, E. Cipolletta, M. Ausili, E. Filippucci, W. Grassi. Clinica Reumatologica, Università Politecnica delle Marche, Jesi (AN), Italy

Background: Gout is a crystal related arthropathy characterized by deposition of monosodium urate (MSU) crystals at articular and periarticular structures. Ultrasound (US) has gained an important role in the diagnosis of gout due to its capability to clearly detect various expressions of MSU crystal depositions in joints, tendons and bursae [1]. The popliteus tendon inserts in a depression on the outer side of the lateral femoral condyle. It has a close connection to the lateral meniscus and is surrounded by the popliteal recess which is in direct communication with the knee joint cavity [2].

Objectives: To evaluate the prevalence of US findings indicative of MSU crystal deposition at the popliteus groove in patients with gout.

Methods: Consecutive patients with gout, diagnosed according to the 2015 ACR/EULAR criteria, and disease controls diagnosed according to the corresponding diagnostic/classification criteria were enrolled. All the patients underwent a bilateral US examination (carried out using a Logiq 9 US system working with a linear probe operating at $15 \mathrm{MHz}$ ) at the popliteus groove level. The US examination was performed with the patient lying supine on the examination bed. A knee flexion of approximately $45^{\circ}$ was necessary to visualize the popliteus groove in the lateral aspect of the femoral condyle just deep to the proximal part of the lateral collateral ligament. The following US abnormalities indicative of MSU crystal depositions were evaluated: isolated shining dots, aggregates (heterogeneous hyperechoic foci that maintain their persistent high degree of reflectivity which occasionally may generate posterior acoustic shadow) and tophi (inhomogeneous hyperechoic/hypoechic material surrounded by a small anechoic rim which may generate posterior acoustic shadows).

Results: We enrolled 17 patients with gout and 22 disease controls: 9 calcium pyrophosphate deposition disease (CPPD), 8 rheumatoid arthritis and 5 psoriatic arthritis. A total 78 popliteus groove were examined by US. US findings indicative of MSU crystal deposition were detected in at least one knee in 13 out of 17 gout patients $(76.5 \%)$ and in 7 out of 22 controls (31.8\%). Table 1 shows the prevalence of the US abnormalities indicative of MSU crystal deposition in the two groups. Six out of the 10 US abnormalities $(60 \%)$ found in controls were detected in CPPD patients.

Table 1

\begin{tabular}{lcc}
\hline & Gout & Controls \\
\hline $\begin{array}{l}\text { Patients } \\
\text { Popliteus grooves assessed by US }\end{array}$ & 17 & 22 \\
$\begin{array}{l}\text { Popliteus grooves "positive" for US findings } \\
\quad \text { indicative of MSU crystal deposits }\end{array}$ & 34 & 44 \\
Isolated shining dots & 23 out of $34(67.6 \%)$ & 10 of out $44(22.7 \%)$ \\
Aggregates & 9 out of $23(39.1 \%)$ & 8 out of $10(80 \%)$ \\
Tophi & 8 out of $23(34.8 \%)$ & 2 out of $10(20 \%)$ \\
\hline
\end{tabular}

Conclusions: These preliminary results suggest that the popliteus groove could be regarded as a sentinel area for detecting MSU crystals. These findings should lead to further investigations aimed at identifying the factors and associated with MSU crystals deposition at popliteus groove level.

\section{References:}

[1] Neogi T, Jansen TLTA, Dalbeth N, et al. 2015 Gout Classification Criteria: An American College of Rheumatology/European League Against Rheumatism Collaborative Initiative. Arthritis Rheumatol 2015;67:2557-68.

[2] Jadhav SP, More SR, Riascos RF, et al. Comprehensive review of the anatomy, function, and imaging of the popliteus and associated pathologic conditions. Radiographics. 2014 Mar-Apr;34(2):496-513.

Disclosure of Interest: None declared

DOI: 10.1136/annrheumdis-2017-eular.4462

\section{AB0864 SENSITIVITY AND SPECIFICITY OF SONOGRAPHIC DETECTION OF URATE CRYSTAL DEPOSITS IN HYALINE CARTILAGE IN PATIENTS WITH GOUT IN YEARLY STAGE}

A. Petrov, V. Fursova, A. Petrov. Medical Academy named after Georgievsky, Crimean Federal university named after V.I. Vernadsky, Simferopol, Russian Federation

Background: In some cases differential diagnosis between yearly gouty arthritis and other types of arthritis is very difficult. In 2015 the sonographic detection of urate crystal deposits in hyaline cartilage as a new criterion was included in set of classification criteria of gout [1]. But diagnostic value of that ultrasound marker in first month of disease is underinvestigated.

Objectives: To investigate sensitivity and specificity of sonographic detection of gouty hyperechoic deposits in hyaline cartilage in patients with gout in comparison with other signs of gout in debut of arthritis.

Methods: The 104 patients with yearly arthritis (duration of symptoms less 
than 6 month) was examined by clinical, laboratory, X-Ray and ultrasonography. After investigation the following diagnoses were made: Gout in 32 patients, Osteoarthritis in 28 patients, Rheumatoid arthritis in 28 patients, Psoriatic arthritis in 16 patients. Ultrasound investigation of affected joints was performed in all subjects by linear probe $18 \mathrm{MHz}$. Urate crystal deposits were seen on the surface of the hyaline cartilage as a hyperechoic thin line or dots on the cartilage, wich sometimes imitate double contour of bones [2,3]. Sensitivity and specificity of ultrasound sign were compared with subcutaneous tophi, bone cysts (X-Ray sign) and hyperuricemia.

Results: The urate crystal deposits in gyalinic cartilage of at least one of affected joints were revealed in 28 of $32(87,5 \%)$ patients with Gout, in 3 of $28(10,7 \%)$ patients with Osteoarthritis and 1 of $16(6,3 \%)$ patients with Psoriatic arthritis. Comparative data of sensitivity and specificity of crystal deposits, bone cysts, subcutaneous tophi and hyperuricemia are represented in table below.

Table 1. Sensitivity and specificity of different diagnostic markers in yearly stage of gout

\begin{tabular}{lcc}
\hline Diagnostic marker & Sensitivity, \% & Specificity, \% \\
\hline Hyperechoic lineal urate deposits in gyalinic cartilage & 87,5 & 94,4 \\
Bone cysts & 21,7 & 88,8 \\
Subcutaneous tophi & 25,0 & 98,6 \\
Uric acid level from $360 \mathrm{mkmol} / \mathrm{l} \mathrm{up} \mathrm{to} 480 \mathrm{mkmol} / \mathrm{l}$ & 46,9 & 86,1 \\
Uric acid level more than $480 \mathrm{mkmol} / \mathrm{l}$ & 34,4 & 97,2 \\
\hline
\end{tabular}

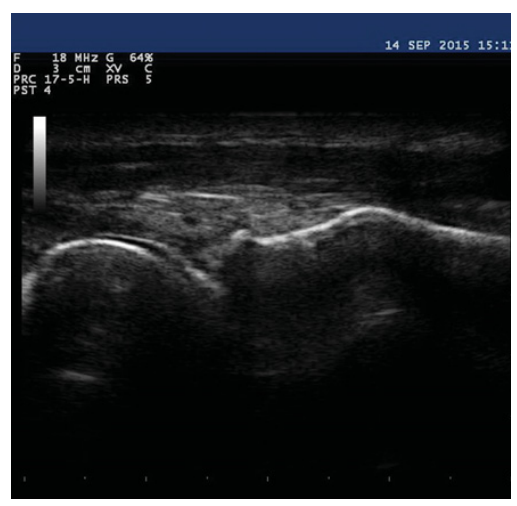

Conclusions: Ultrasound detection of urate crystal deposits in hyaline cartilage in patients with gout in yearly stage has a high sensitivity and comparable level of specificity with other diagnostic markers of Gout.

References:

[1] Neogi T et al. Gout classification criteria: an American College of Rheumatology European League Against Rheumatism collaborative initiative. Ann Rheum Dis. 2015;74(10):1789-1798.

[2] Filippucci E., Di Geso L, Grassi W. Tips and tricks to recognize microcrystalline arthritis. Rheumatology 2012;51(7):18-21.

[3] Naredo E et al. Ultrasound-detected musculoskeletal urate crystal deposition: which joints and what findings should be assessed for diagnosing gout? Ann Rheum Dis. 2014;73(10):1522-1528.

Disclosure of Interest: None declared

DOI: 10.1136/annrheumdis-2017-eular.1292

\section{AB0865 SERUM URATE AND ITS ASSOCIATION WITH RACE IN YOUNG ADULTS: BASELINE ANALYSIS FROM A RANDOMIZED CLINICAL TRIAL}

M.B. Saddekni ${ }^{1,1}, \underline{\text { A.L. Gaffo }}^{2}$, P.J. Foster ${ }^{1}$, S.R. Biggers ${ }^{2}$, E.J. Rahn ${ }^{2}$, P. Li $^{3}$ K.G. Saag ${ }^{1} .{ }^{1}$ UAB School of Medicine, Division of Clinical Immunology and Rheumatology; ${ }^{2}$ Department of Medicine, Division of Rheumatology and Immunology; ${ }^{3}$ UAB School of Public Health, Department of Biostatistics, University of Alabama at Birmingham, Bimringham, United States

Background: Increased levels of serum urate (sUA) have been reported in association with hypertension, chronic kidney disease and obesity. All these conditions are over-represented in US African Americans, who also have greater environmental risk factors for hyperuricemia development including elevated fructose intake. Our group has previously reported that young African Americans have lower sUA concentrations than Caucasians after adjustment for clinical and demographic factors.

Objectives: To determine whether there is a differential association between sUA and race in young adults.

Methods: We examined baseline data on consecutively enrolled individuals (age 18 - 40 years) in an interventional study aimed at lower blood pressure (BP) through the administration of urate-lowering therapy. African Americans were over-represented in the sample by study-design. Inclusion criteria included a SUA of $\geq 5.0 \mathrm{mg} / \mathrm{dL}$ for men or $\geq 4.0 \mathrm{mg} / \mathrm{dL}$ for women. After means comparisons between races, we performed multivariable adjustments for age, gender, BP, and body mass index (BMI) a multiple linear regression model. Data reported are mean \pm standard deviation.
Results: 86 participants recruited from Birmingham, AL were included in the analysis. Participants had a mean age of $28.5 \pm 6.9$ years, $36 \%$ were female, $41 \%$ were African Americans (AAs), and the mean BMI was $29.2 \pm 6.8 \mathrm{~kg} / \mathrm{m}^{2}$. The mean sUA was $5.9 \pm 1.2 \mathrm{mg} / \mathrm{dL}$ ( $\mathrm{n}=77$, range: 3.9 to $8.5 \mathrm{mg} / \mathrm{dL}$ ). We found a significantly lower sUA for African Americans compared to persons of other races $(5.4 \pm 1.2$ $\mathrm{mg} / \mathrm{dL}$ vs $6.2 \pm 1.1 \mathrm{mg} / \mathrm{dL}, \mathrm{p}=0.005)$. After multivariable analysis the difference in sUA between AAs and other races was attenuated to non-significance $(p=0.33)$ due to the effects of BMI and gender. As expected, the association between sUA and gender was significant (Table).

Table 1. Multivariable regression model on the association between serum urate and race among young adults $(n=86)$

\begin{tabular}{lcc}
\hline Variable & Estimate $(95 \%$ confidence interval) & $\mathrm{p}$ \\
\hline Race (African-Americans versus other races) & $-0.34(-0.82,0.15)$ & 0.18 \\
Age (per year) & $0.02(-0.02,0.05)$ & 0.34 \\
Gender (men versus female) & $1.36(0.87,1.85)$ & $<0.001$ \\
BMI (per unit of $\left.\mathrm{kg} / \mathrm{m}^{2}\right)$ & $0.04(0.00,0.07)$ & 0.035 \\
\hline
\end{tabular}

$\mathrm{BMI}=$ Body-mass index.

Conclusions: In this cross-sectional analysis of young adults, AAs had lower sUA concentrations than other races. However, this difference is explained by the effect of gender differences in SUA and BMI. A potential limitation is that participants were enrolled after they met a sUA threshold so not all the ranges of sUA in a normal population are represented in this analysis. Larger studies will be needed to fully address this question.

References:

[1] Feig, D.I., JAMA, 2008. 300(8): p. 924-32.

[2] Fang, J. JAMA, 2000. 283(18): p. 2404-10.

[3] Gaffo, A.L. Arthritis Res Ther. 2012 Jan 6; 14(1):R4.

Acknowledgements: National Institute of Arthritis and Musculoskeletal and Skin Diseases P50AR060772, K24AR052361 (to KGS).

Disclosure of Interest: M. Saddekni: None declared, A. Gaffo Grant/research support from: Amgen, AstraZeneca, Consultant for: Cymabay, Ardea, Employee of: US Government, P. Foster: None declared, S. Biggers: None declared, E. Rahn: None declared, P. Li: None declared, K. Saag Grant/research support from: AstraZeneca, Crealta, Takeda, Consultant for: Ardea/AstraZeneca, Crealta, Takeda

DOI: 10.1136/annrheumdis-2017-eular.5390

\section{AB0866 EVALUATION OF THE ACHIEVEMENT OF A THERAPEUTIC TARGET OF $<6$ MG/DL IN ALGERIAN PATIENTS TREATED FOR GOUT}

B. Bengana ${ }^{1}$, S. Slimani ${ }^{2}$, K. Testas $^{3}$, F. Rahal ${ }^{4}$, M. Makhloufi ${ }^{5}$, A. Ladjouze ${ }^{4}$, S. Lefkir-Tafiani ${ }^{1} .{ }^{1}$ Rheumatology, Derpartement of Rheumatology -University Medical Centre Beni Messous, ALGIERS; ${ }^{2}$ Rheumatology, University of Batna, Batna; ${ }^{3}$ Rheumatology, El kherroub Hospital, Constantine; ${ }^{4}$ Rheumatology, Ben Aknoune Hospital, ALGIERS; ${ }^{5}$ Medicine, University of Batna, Batna, Algeria

Background: Gout is one of the most prevalent rheumatic conditions in the developing world, due of the aging of the population and the modifications in the life style. The 2014 EULAR recommendations for the management of gout have defined the therapeutic target of $60 \mathrm{mg} / \mathrm{L}$ for gouty patients (recommendation 8). The aim of the study was to assess the adherence of Algerian patients with gout to these recommendations.

Methods: We have retrospectively analyzed patients files aged 18 and more, followed in a rheumatology setting for gout, in 4 centers in Algeria. Demographic, clinical and lab data were collected. We have excluded files with missing data. Were noted the used therapeutics and serum uric acid in every patient through time. Tolerance was noted.

Results: We have analyzed 145 complete files: 98 men (68\%), with a mean age of $65.4 \pm 11.4$ years. All patients except two had rheumatic manifestations, 20 patients had renal insufficiency and 15 had tophi. Main comorbidities were hypertension ( 40 patients) and diabetes ( 25 patients). The mean serum uric acid level was $96 \pm 14 \mathrm{mg} / \mathrm{L}$. Concerning symptomatic drugs, 81 patients have taken colchicine and 15 NSAIDs, the remaining patients have taken other drugs or combination therapy. All patients but one have received serum uric acid lowering therapy (allopurinol in majority of cases), with a median dosage of $200 \mathrm{mg} / \mathrm{day}$, and only 5 patients taking more than $300 \mathrm{mg} /$ day. The mean serum uric acid level at 6 months was $58 \pm 14 \mathrm{mg} / \mathrm{L}$, with $58 \%$ of patients achieving a level of $<60 \mathrm{mg} / \mathrm{L}$. Conclusions: In rheumatology settings in Algeria, more than $93 \%$ of gouty patients received allopurinol, with an excellent tolerance. However, it seems that dosage is insufficient, with only $58 \%$ of patients achieving the EULAR recommendation 8 . More efforts have to be provided to optimize this therapy.

Disclosure of Interest: None declared

DOI: 10.1136/annrheumdis-2017-eular.4031 